BULLETIN Bulletin hispanique

HISPANIQUE Université Michel de Montaigne Bordeaux

111-1 | 2009

Varia

\title{
Francisco Delicado, La lozana andaluza
}

Galaxia Gutenberg, Barcelona, 2007

Joseph Perez

\section{CpenEdition}

Journals

Édition électronique

URL : http://journals.openedition.org/bulletinhispanique/964

DOI : 10.4000/bulletinhispanique.964

ISSN : 1775-3821

Éditeur

Presses universitaires de Bordeaux

\section{Édition imprimée}

Date de publication : 1 juin 2009

Pagination : 281-282

ISBN : 978-2-86781-586-7

ISSN : 0007-4640

Référence électronique

Joseph Perez, «Francisco Delicado, La lozana andaluza », Bulletin hispanique [En ligne], 111-1 | 2009,

mis en ligne le 10 juillet 2012, consulté le 23 septembre 2020. URL : http://journals.openedition.org/

bulletinhispanique/964 ; DOI : https://doi.org/10.4000/bulletinhispanique.964 
COMPTES RENDUS

Francisco Delicado, La lozana andaluza. Edición y estudio preliminar de Jacques Joset y Folke Gernert. Centro para la edición de los clásicos españoles. Galaxia Gutenberg. Círculo de lectores, 2007, 596 p.

Cette édition, publiée dans la Biblioteca clásica que dirige Francisco Rico, se recommande par la qualité et la sûreté de l'appareil critique, des annotations et des commentaires de Jacques Joset et de Folke Gernert. Elle reprend, au besoin pour les rectifier ou les améliorer, les observations des éditeurs précédents, notamment celles de A. Vilanova (Barcelone, 1952), B. M. Damiani (Madrid, 1969), G. Allegra (Madrid, 1980), C. Allaigre (Madrid, 1985)... Les leçons retenues et les explications proposées sont convaincantes, sauf sur quelques points secondaires. La Lozana abonde en mots et en phrases équivoques de caractère érotique ; il n'était pas nécessaire d'en rajouter et de voir du sexe partout ${ }^{1}$. On est sceptique aussi sur les commentaires au mamotreto II : on y vante les compétences culinaires de Lozana et les éditeurs y voient une allusion à des coutumes juives ou moriscas; il s'agit plus simplement de cuisine méditerranéenne, à base d'huile d'olive et de fritures, alors que, dans la Meseta - et l'Andalousie repeuplée par les Castillans -, on préférait le lard et le pot-au-feu. Au moment de l'expulsion des juifs, le chroniqueur Bernáldez, curé de Los Palacios, ne s'y trompait pas: [Los judios] nunca perdieron el comer a costumbre judaica de manjarejos y olletas de adefina, manjarejos de cebollas y ajos refritos con aceite, y la carne guisaban con aceite, ca lo echaban en lugar de tocino y grosura por excusar el tocino. On s'étonne enfin que les éditeurs, qui, en commentant le mamotreto LXII, rappellent opportunément la légende du juif errant, ne l'aient pas évoquée en annotant le mamotreto XVI : les cinq écus qu'on demande à

1. On pense en particulier à la note 21.15 de la p. 386 : «se puede relacionar otra vez Ven-ecia con Venus».

$B H i$, Tome 111, n $^{\circ} 1$ - juin 2009 - p. 281 à 304. 
Lozana pour prix d'un diamant représentent bien le capital d'un juif, mais à condition de penser aux cinq pièces de monnaie que le juif errant avait toujours en poche.

Joseph PÉREZ

Francia mira la Guerra de la Independencia. La guerra en la literatura francesa del siglo XIX. Marta Giné (ed.). - Lérida, Milenio, 2008. - La Guerre d'Indépendance espagnole dans la littérature française au XIX'e siècle. L'épisode napoléonien chez Balzac, Stendhal, Hugo... Marta Giné-Janer (éd.). - Paris, L'Harmattan, 2008. - ISBN : 978-2-296-07605-1.

Cet ouvrage, produit dans le contexte de la commémoration du bicentenaire des événements de 1808, rassemble des extraits de dix œuvres littéraires françaises, publiées entre 1814 et 1868, traitant à des niveaux différents de la Guerre de l'Indépendance. Ces œuvres, parfois peu connues bien qu'écrites par quelques-uns des meilleurs auteurs de l'époque, ont été choisies non seulement comme un témoignage de la trace laissée par l'événement historique dans l'imaginaire français du XIX ${ }^{\mathrm{e}}$ siècle, mais aussi en raison de leur qualité littéraire. Les textes sont précédés d'une introduction, due à onze universitaires espagnols ou français, qui situe l'extrait dans son contexte de référence et dans l'œuvre de son auteur. L’originalité du projet, qui s'inscrit dans un programme de recherche subventionné par le Ministère espagnol de l'Education, consiste en sa présentation en deux volumes, l'un en français, l'autre en espagnol dans lequel chaque texte littéraire a été traduit par le chercheur chargé de sa présentation.

Le premier texte, tiré des Mémoires sur la guerre des Français en Espagne (1814) d'Albert de Rocca, lieutenant du deuxième régiment des Hussards de l'armée napoléonienne, est le seul témoignage retenu parmi les nombreux récits de combattants de la guerre, mais il s'agit ici d'un combattant bien particulier puisque son mariage avec Germaine de Staël lui valut d'être poursuivi et considéré comme déserteur par Napoléon. Les différents extraits choisis par Nathalie Bittoun (Universitat Oberta de Catalunya) font alterner la description de la foule bigarrée des marchés de Madrid et celle des combats dont la cruauté n'est pas sans évoquer certaines planches des Désastres de la guerre. Mais ils mettent surtout en exergue les réflexions sur la résistance populaire qui conduisent l'auteur, à partir de l'importance qu'il accorde au concept de " nation ", à critiquer sévèrement les conditions dans lesquelles a été engagée cette campagne militaire pour dégager les causes de la défaite française. 